\title{
The World Bank, Community Schooling, and School-Based Management: A Political Economy of Educational Decentralization in Nepal ${ }^{1}$
}

\author{
Tejendra J. Pherali
}

Liverpool John Moores University, United Kingdom

Email:T.Pherali@ljmu.ac.uk

\section{Introduction}

Community involvement in educational development in Nepal is nothing new. Even during the Rana oligarchy (1846 to 1950 ), when public education was considered a threat to the regime and educational initiatives were a punishable act, local communities made efforts to establish schools and learning centers, often risking their lives to do so. In 1951, there were 321 primary schools and 11 secondary schools in Nepal; this number had increased to 4,000 by 1971 , when the Panchayat polity (1960 to 1990) introduced the National Education System Plan (NESP) to nationalize all public schools. The NESP has been referred to as the “most politically significant education policy" (Caddell, 2007, p. 15) in Nepal. Centralized education was to replace dominant educational traditions with a supposedly egalitarian model of education that would provide technical support and funding from the government to improve the quality of education.

However, the political motive of the NESP was "to strengthen devotion to crown, country, national unity and the Panchayat system" (MoE, 1971, p. 1) and legitimize the regime and its ideologies (Apple, 2004) by homogenizing the country's diverse cultural and linguistic traditions. A national curriculum was introduced to "synthesise diverse socioeconomic interests, negotiate ethno-lingual heterogeneity and convert the geopolitical entity of Nepal into an emotionally integrated nationhood" (Mohsin, 1972, pp. 35-36). Textbooks

\footnotetext{
${ }^{1}$ To cite this paper: Pherali, T. J. (2012) The World Bank, Community Schooling, and School-Based Management: A Political Economy of Educational Decentralization in Nepal. In D. Kapoor, B. Barua, and A. Datoo (Eds.), Globalization, Culture and Education in South Asia: Critical Excursions, New York: Palgrave McMillian.
} 
were centrally produced and distributed to all schools throughout the country and reflected the Panchayat ideology - monarchy, Hinduism, and Nepali language (Onta, 1996).

Nevertheless, in spite of significant policy reform and national investment, the quality of public education and the efficiency of school management remained relatively poor compared to the private schools established in the late 1990s. These private schools continuously outperformed government schools in the School Leaving Certificate (SLC) examinations (World Bank, 2003). Hence, over the years, the national education system strengthened elitism and led to the systematic marginalization of indigenous nationalities, minority ethnic groups, and Dalits (the untouchable castes).

In response to the weak performance of public schools, the Seventh Amendment of Education Act was introduced in 2001, which allowed for a transfer to school-based management. This did not emerge only in the context of Nepal's struggle for educational reforms; it was also greatly influenced by the global discourse of neoliberalism, which rationalizes decentralization as a means of enhancing accountability, quality, ownership, and efficiency in the public sector (World Bank, 2003).

In this chapter, I discuss how the global policy discourse of school-based management interacts with local socioeconomic realities and political scenarios in Nepal. In this process, I will be drawing on interviews I conducted with SMC members, parents, teachers and political leaders as part of a multi-agency funded study into political economy analysis of education in Nepal. These interviews were carried out in two private and six government-funded schools in Dhanusha, Kapilvastu, Kathmandu and Rupandehi districts of Nepal and primarily focused in identifying political economy drivers of educational management within the context of decentralisation in education. I argue that unintended outcomes of decentralization in education have manifested in the form of excessive politicization, corruption, and tensions in the school system.

\section{School-Based Management: A Global Policy Discourse}


The publication of the World Bank document Priorities and Strategies for Education (World Bank, 1995) marked the formal beginning of the global drive for educational decentralization. It has primarily impacted educational reforms in the developing world. The document is inspired by neoliberal concepts of deregulation, privatization, and marketization in education. In this document, the funding mechanism of public education was proposed as involving:

local rather than central government taxation; cost-sharing with local communities; the use of block grants; the charging of fees at higher levels of education; the encouragement of revenue diversification; the use of "portable" capitation grants, vouchers and student loans; and funding based on output and quality. (World Bank, 1995, p. 131)

Most developing countries are already struggling to manage their public services and have had no choice but to subscribe to this policy shift. The gradual process of state withdrawal from education has hence become a major symptom of a neoliberal attack on already malfunctioning education systems in the developing world.

School-based management is considered a radical form of educational decentralization that enhances participation of local stakeholders. It involves "the transfer of decision-making authority, responsibility and tasks from higher to lower organizational levels or between organisations" (Hanson, 1998, p. 112; McGinn \& Welsh, 1999). Educational decentralization is often argued "to increase both the productivity and efficiency of educational delivery systems, based on a presumption that local actors are better equipped to make appropriate decisions for their local context and better able to hold local actors accountable" (Edwards, 2011, p. 69).

Decentralization is often driven by the motives of governments or international agencies and is based on the assumption that policy aims and objectives are shared by all stakeholders at community levels (McGinn \& Welsh, 1999); however, this can lead to problems in terms of access to and quality of education, teacher professionalism, and participation of civil society in the provision of education (Carnoy, 1999; Poppema, 2009). As 
Carney, Bista, and Agergaard (2007) argued, "most decentralisation initiatives have struggled to realise their goals" (p. 614) due to a disconnection between policy aims and local capacities. As a result, policy aimed at mobilizing parents and communities fails to reach its intended stakeholders or the authority devolved to the local level is captured by unintended agents who manipulate policy reforms to work in their favor (Edwards, 2011).

When education is decentralized, local communities in low-income countries are burdened with the responsibility of school management (Poppema, 2009). Since structural inequalities threaten stability, devolution of authority is seen as a strategic intervention of the neoliberal state to neutralize political opposition and reduce the chances of outbreak of violent conflicts (Cornwall \& Brock, 2005). Clearly, this approach to conflict prevention ignores the fundamental problems of social injustice in these societies. Hence, delegation of educational responsibility to local communities perpetuates the status quo in the society and exploits the poorest by making them contribute to the state's fundamental duty of providing basic education to its citizens (Poppema, 2009). Local educational reforms, however, are influenced by the complex processes of globalization, which are dominated by the ideologies of international organizations such as the World Bank (Watson, 2000).

On the global scale, political and economic processes of globalization have contributed to a massive growth in knowledge industries, leading to "differential effects" on nation states and their educational institutions (Zajda \& Geo-Jaja, 2009, xix). As a result, the major goal of educational reforms has been to maximize efficiency and economic productivity by internationalizing educational processes (e.g., access to education, standardization of curriculum and assessment techniques, meritocracy, etc.). This largely undermines the agenda of educational equality. In addition, the advancement of information technology and innovation in the global market calls for a multitasking flexible workforce (Carnoy, 1999); education systems are expected to fulfil the needs of the world market. In particular, education systems in the developing world are under pressure to produce an educated labor force that can attract global financial capital, which is seen as the only rescuer of the world poverty. This comes with a "private-sector bias" that promotes market 
competition, smaller public sectors, and often dismantling of the welfare state (Carnoy, 1999, p. 16). As a consequence, there is indirect pressure on the governments of developing countries to promote mechanisms that reduce public spending while expanding the provision of education. This can only be done by devolving authority and ownership of educational institutions to communities, who are then held accountable to their governments for public education. Hence, education decentralization involves not just the devolution of power to indigenous people or communities, but also an ideological action that facilitates systematic delegation of financial responsibilities, which promotes economic and self-functioning mechanisms that are expected to produce public returns at the public's cost. Thus, the ultimate beneficiary of neoliberalism is the private sector and the mega structures of global capitalism where the educated workforce is likely to be absorbed.

\section{Educational Decentralization in Nepal}

Proponents of educational decentralization often argue that educational development in Nepal, which has included establishing and managing public schools has mostly been community-driven. However, since the Education Act of 1971, which nationalized all the schools that were initially established by local people and managed using mainly local resources, the relationship between communities and schools gradually became ceremonial. Also, the notion of community is problematic, since communities in Nepal represent ethnic and caste-based hierarchies and are not homogeneous (Carney et al., 2007).

In the post-1950 period, privileged social groups (mainly Brahmins, Chhetris, and Newars) were able to seize the opportunity of educational freedom and establish schools and learning centers in their own neighbourhoods, thus providing education for their children, and consequently exacerbating horizontal inequalities (Stewart, 2008) along caste and ethnic lines. Despite increased provision of education and the consistent improvement in school enrolment, educational outcomes in Nepal are usually inequitable across different castes and ethnicities. Upper caste groups, males, and hill-based ethnic groups have been the principal beneficiaries of the education system as compared to the subordinate castes (e.g., Dalits), indigenous nationalities, and Madheshi, the ethnic people in the Southern 
flatlands. These disparities are not solely explained by economic factors, however, but also by the varied social and cultural capital of these groups who do not have the habitus-a set of socially acquired dispositions, skills, and ways of cultural interaction (Bourdieu, 1984)_ needed to achieve their full potential in education.

Educational decentralization in Nepal was taken up aggressively in 2001 with the Seventh Amendment of Education Act of 1971. The amendment renamed all government schools as community schools and established a policy to delegate authority of school management to the district and village development committees. As a result, the role of SMCs became significant in each school's operation, as well as in supervising teaching and learning, recruiting teachers, managing the school budget, and mobilizing local resources. There were also a number of other policy regulations that laid foundations for the systematic transfer of school management authority to local communities. For example, the Education Rules 2002, the Operational Manual for Community Managed Schools 2002, and more importantly the World Bank funded Community Schools Support Project (CSSP) collectively created a policy framework for community schooling.

However, there are two fundamental challenges within this policy reform. First, the assumption of the community as a homogeneous entity and characterized by fellowship, harmony, and social cohesion is highly problematic (Carney et al., 2007) in Nepal. Nepali communities represent tremendous diversity along socio-cultural, economic, religious, ethnic, caste, and linguistic spheres. Unequal power relations and social hierarchies among groups mean that the degree of influence in community participation can vary significantly. In Nepal, there is a strong patronage system, meaning that the involvement of local communities in school management processes is highly selective and is often motivated by the political and economic interests of stakeholders at different levels.

A second challenge to the policy reform is the limited extent to which local communities can be involved in the functioning of the school. For example, schools must follow the national curriculum and use the prescribed textbooks published by the government. In addition, the District Education Officer who is accountable to the Department of Education 
has full authority to dissolve the SMCs that cannot deliver their responsibilities at prescribed standards. This means that the decisions of the SMCs are always under the influence of District Education Officer, who oversees the implementation of the policy.

In contrast, the private education sector, which educates roughly 14 percent of students (DoE, 2010) is unaffected by most education policies (e.g., decentralization, education in mother tongue). The majority of politicians, bureaucrats, policy makers, social elites, and the urban rich educate their children in fee-paying English-medium private schools. This means that most policy interventions affect the children from the bottom of society while children from wealthier and more privileged backgrounds benefit from what tends to be seen as better quality education. The consistent underperformance of government schools has significantly damaged the reputation of public education. As a result, there has been a significant increase in the number of private schools in the last decade (DoE, 2010).

However, in the interviews, teachers from both private and public schools revealed that private schools promote western values and lifestyles, which are generally "away from dominant social and cultural realities of Nepal" (interview with a private school teacher in Kathmandu). There is also increasing evidence that suggests that private education reproduces elitism and perpetuates social divisions and injustice in society (Dorling, 2011). For example, private education is viewed as a marker of social status and those with English-medium private school education can seize economic opportunities in the Englishlanguage market (i.e., private businesses such as banks and the massive INGO sector).

The perceived superiority of private education and its western orientation indicates an increasing influence of external factors on the national education system. That is, education is becoming synonymous with serving the purpose of global economic market, rather than the local economies through relevant education and skill training. As a result, modern educational processes are less appreciative of indigenous knowledges and the needs of local economies such as cottage industries and sustainable agriculture. Thus youth 
measure their educational successes against parameters set by the global economic market rather than the social and economic needs of their local settings.

When neoliberal policy prescriptions travel to local levels, they tend to interact with various political economy drivers, leading to disconnections between national and global as well as local and national levels, often producing unintended outcomes such as corruption, politicization, and 'capture' (Edwards, 2011) of the benefits of decentralization. In the following section, I discuss some of these tensions in education from the political economy perspective.

\section{The Political Economy of Community Schooling}

Political economy analysis is concerned with "the interaction of political and economic processes in society: the distribution of power and wealth between different groups and individuals, and the processes that create, sustain and transform these relationships over time" (Collinson, 2003, p. 3). While education decentralization has given local communities access to school funds, it is the traditionally privileged groups (mainly the upper castes) who usually hold political prominence in the community are most likely to influence the selection of the SMCs. Because schools are "the site(s) of political and social influence" (Edwards, 2011, p. 78), decentralization contributes to sustaining and reproducing traditional power relationships rather than transforming them in favor of marginalized groups, such as women, Dalits, Tharu, Madheshi, and other indigenous nationalities who continue to be marginalized in local political and educational processes. The decade-long civil war (1996 to 2006) has often been rationalized as a means to transform the rigid horizontal inequalities across these social and cultural groups (Tiwari, 2010) and to achieve a more just and equitable social order (Bhattarai, 2003). However, the absence of elected government bodies at local levels for over a decade created political spaces in schools where the struggle for political dominance, for example, through the SMCs, became a common phenomenon. The return of peace as a result of the peace accord simply reduced the amount of direct violence but the fundamental causes of social inequalities, uneven development, and economic grievances (Bhattarai, 2003; Deraniyagala, 2005) have not yet 
been dealt with. Thus, any policy initiative in the education sector that does not fully appreciate the social context is likely to serve the interests of the privileged groups in society rather than promote equality and social inclusion.

Most SMC members who were interviewed in this study had close affiliations with political parties and many of them held responsible positions in the local or regional party committees. The analysis of interviews with parents, teachers, and members of the SMCs revealed that there are social and political benefits to being involved in local educational committees such as SMCs, Parent-Teacher Associations, or Social Audit Committees. An SMC chair in Kapilvastu mentioned that his responsibility in the SMC provided him with an opportunity to serve the community in other avenues of social services, such as politics. In most schools that participated in the study, the SMC chairs belonged to upper castes and were influential personalities in the local communities. Edwards (2011) likewise noted that the SMC Chair usually has high social status in the community and it is considered "a place to gain political prominence" (p. 79). As SMC Chairs usually hold reputable positions in their political parties, they have significant influence on teachers and parents in the community. In theory, the SMC should reflect a wide range of stakeholder interests, including representatives of women, Dalits, and marginalized groups in society, but in reality, the SMC Chair dominates the committee and the regulations about its functions are often undermined.

For example, in a secondary school in Kapilvastu, where 95 percent of the children come from Tharu communities, the SMC chair belongs to a non-Tharu ethnic group. He is able to secure this role because of his social prominence and political affiliation to one of the national political parties. In a community school in Kathmandu, the SMC chair is an influential businessman and is highly regarded in his local community for his significant financial contribution to the development of the school playground. Neither of these SMC Chairs are guardians or parents of any children in the school. A study conducted by Research Centre for Educational Innovations and Development (CERID, 2006) found that only 34 percent of the SMC Chairs were parents or guardians of children in the school and 
although the government has amended the regulation specifying that only a parent could be eligible for the SMC membership, this rule is mostly ignored or manipulated.

Interestingly, the analysis of interviews with SMC members and headteachers shows that educational success is measured in terms of infrastructural development such as construction of school buildings, playgrounds, and fences around the school. Teachers and SMC members in Dhanusha strongly argued for a fence around the school to prevent children from escaping during school hours. Most SMC members felt that the physical barrier around the school would oblige children to stay inside the school and learn. However, none of the members had ever observed the poor quality of teaching and learning that took place inside the classroom. In most interviews, SMCs and head teachers rarely mentioned children's learning, teacher development, or quality of educational experience.

Another perceived measure of school development for both head teachers and SMC Chairs was a school upgrade, which would not only provide higher-level schooling for children locally, but also help SMC Chairs and head teachers gain social prestige for their achievement. However, an educational officer in Kathmandu mentioned that school upgrading and the subsequent construction of extra classrooms often involved corruption. He revealed

We often receive complaints from opposing groups of the SMCs about the misuse of school funds. This is more likely to happen where the head teacher and the SMC chair have good working relationships and share the same political views. Even the District Education Officer [DEO] is sometimes involved in this kind of corruption. (Education Officer in Kathmandu) In the southern districts of the Terai (southern plains bordering India), corruption and malpractice are reported by SMC members to be pervasive in the process of teacher recruitment and redeployment. One SMC member in Kapilvastu stated that "there are different rates for recruitment in different teaching grades: 100, 200, and 300 thousand Nepalese rupees for a primary, lower secondary, and secondary level post, respectively" (Focus group interview with SMC members and local politicians in Kapilvastu). It appears 
that this type of corruption is pervasive in these schools and occurs at different levels involving SMC chairs, DEOs, head teachers, and school auditors. Community schooling seems to have been perceived as a means to gain increased access to school funds rather than achieving improved educational quality by enhancing local capacities and better engaging teachers and parents in their children's learning. It suggests that there is a disconnection between the policy aims and socio-political realities at the local level.

\section{Local Capacities, Teachers, and School Management}

The nationalisation of schools and pedagogies in 1971 gradually disconnected communities as a whole from educational processes and systematically centralised the educational authority. The increasing horizontal inequalities across different ethnic and caste groups, fuelled by biased education system (e.g. medium of instruction, teaching workforce, cultural references in pedagogies etc.) structurally resisted inclusive representation and community empowerment. This simply perpetuated social and political disparities in communities, where only the privileged social groups were able to influence community decision-making. In this context, educational decentralization, designed at the national level and influenced by external agencies, largely ignores the realities of local level capacities and interests to manage schools. As noted elsewhere, roles and responsibilities of SMCs lack clarity within the policy guidelines (Carney et al., 2007; World Bank, 2010) which may potentially lead to management uncertainties among local stakeholders. SMC members who participated in the interviews in Kapilvastu, Dhanusha, and Kathmandu were unaware of any training available to them in order to support their school management role. Even though the policy states that SMC members can also observe lessons, only the SMC Chairs who were educated and genuinely interested in the educational processes were likely to do so; however, most SMC members I interviewed reported that they did not observe lessons. While the idea of observation is appreciated by head teachers and SMC members, they were not clear about to observe (e.g. teaching methods, classroom setting, behaviour management, student engagement in learning activities etc.). Most importantly, the majority of SMC members in rural schools were not necessarily educated or trained to an extent that 
they could provide constructive feedback to qualified teachers on teaching and learning. Hence, most SMCs monitored teacher absenteeism and focused their work on infrastructural development of the school depending on availability of funding.

There tend to be underlying tensions between teachers and SMCs since the teacher unions have always resisted the transfer of school management to local communities citing this as a state policy of gradual disengagement in the delivery of public services and, most importantly, a threat to their job security. Almost all teachers are affiliated to a teachers association that operates under the umbrellas of different political parties. With their political connections, teachers can neutralize the risk of their unintended transfer by the DEO and create a favorable working environment where they can enjoy the privileges of a flexible timetable and reduced workload. For example, in Kathmandu's public schools, most secondary level teachers have second jobs in private colleges. A deputy head teacher in Kathmandu revealed that some teachers had abused their profession with the patronage from their political parties.

We have a fulltime teacher who arrives at 12PM and leaves at 4PM.

Sometimes he disappears from school during his teaching hours without even informing the head teacher. I think he works in a private college during his fulltime teaching hours here. The school management cannot do anything to him because he is associated with a Maoist teachers' union. (A Deputy Head Teacher in a Community School in Kathmandu)

Even the DEOs are unable to stand up to the teacher unions, which undermines the DEOs' work of monitoring and supervising schools and delivering continuing professional development opportunities for teachers. In a few districts in the southeastern part of the Terai, most of the officials have given up trying to do their jobs and remain in the District office. The state failed to provide personal and professional security to teachers in most rural parts of the country during the decade-long civil war. Since the peace agreement, the state has not yet regained full trust from teachers who have responded to their traumatic 
experiences by negotiating their loyalty with political associations that extend teachers' professional security.

\section{Politicization of School Management Committees}

Because the role of an SMC Chair generally provides political and economic benefits, the SMC Chair has become a competitive position. As a result, many schools hold elections for their SMCs. Especially in the Terai, securing the position of SMC Chair has become the subject of intense political competition, especially where there are school lands and properties generate extra income. In the absence of elections for local governments, the election of SMC Chairs presents practically the only opportunity for political parties to measure their strength. The ferocity of these elections may arise from this factor rather than from any concern for education. A recently elected SMC Chair who is also a senior political leader of Terai-based political party lamented

I had to spend NRS.40,000 [US\$500] to win the election for the SMC chair. Other parties also supported me in this election as I had helped them gain a good number of votes during the elections for the Constituent Assembly. It

[the election] became an issue of my social and political prestige. (A recently elected SMC Chair in Kapilvastu)

It is interesting to observe that the SMC elections take place in the same manner as any other parliamentary elections and likewise involve expensive political campaigns. The SMC Chair cited above is also a district president of the regional party and running for Chair also became a test of his political influence in the district. However, getting a consensus to hold elections is also not without hassles. A head teacher from a community school in the north of Kapilvastu revealed the difficulty of forming a new SMC.

A former UML [local] leader who has been the SMC Chair of my school still intends to continue but now there are other two candidates - one from the Maoists and the other from Nepali Congress interested in the post. It is likely that elections will be held this time. But the present SMC members who are mainly linked with UML would not allow me to invite parents for a boarder 
consultation to form a new SMC and the School Inspector who represents the SMC selection committee was warned by local political leaders not to interfere in the selection process. (Head Teacher from a Secondary School in Kapilvastu)

The DEO has been converted to a 'Complaint Office': officials are mostly occupied dealing with complaint from schools. Mainly, these are about political favoritism of the SMC in temporary teacher recruitment, corruption in teacher recruitment, misuse of school funds by the head teacher or SMC or both (e.g., not distributing scholarships, failure to form the SMC due to tensions between contesting groups, unfairness in the elections of SMCs, and complaints against a previous DEO's decisions). For example, it was reported that 25 relief quota teachers recruited by one of the previous DEOs in Kapilvastu district did not teach in any school but were paid a full salary and attended district level training to gain additional daily allowance.

\section{Issues with Community School Management: A Political Economy Analysis}

The vignette below drawn from my diary during the fieldwork represents a typical political tension that occurs in rural districts.

It is 11AM; a group of teachers from a secondary school were picketing at the entrance of the District Education Office. No DEO staff members, apart from an Office Assistant, have arrived yet, even though work was supposed to start at 10AM. The DEO was reported to be on leave for four days and had given his charge to a lady officer who arrived only around $1 \mathrm{pm}$. The story of the teachers' protest in front of the DEO unfolded interestingly. They had not been paid for the past four months due to schoolbased tensions related to the appointment of a new head teacher. The previous head teacher had recently retired giving his deputy the authority of headship. The new head teacher, though was able to acquire an appointment letter from the district education office, was rejected by most teachers but the SMC Chair. However, the school accounts had not been transferred to the 
new head teacher so he could not sign the cheques for teachers' salaries.

The school generated some additional income by renting out its properties, including to some shops. Clearly, there was a potential for economic gains from school funds, which encouraged a struggle for the post of SMC Chair and head teacher.

To achieve a new political combination of the head and SMC, an individual who had the support from a prominent regional political party forcefully replaced the SMC Chair and illegally captured the SMC. Now, the new SMC, with the support from the newly appointed DEO in the district, transferred a secondary level teacher from a different school into this school to replace the new head. But the head teacher was not prepared to renounce his post as he claimed, had been formally appointed to the post. The new DEO could not approve the transfer of school accounts to anyone at this situation and hence the teachers' salaries were withheld. The school had been closed for the past week, as the teachers demanded the appointment of a new head teacher and payment of their salaries without any further delay. The current head teacher had the patronage from teachers' union as well as from Nepali Congress Party. The DEO was suspected of being bribed and was therefore hesitating to make a new decision.

The position of SMC Chair provides a significant opportunity to control resources and extend patronage networks. While the SMC Chair may have strong political links and simultaneously hold positions in the party, this is not so evident in the case of head teachers, even though they might hold positions in teacher associations that are linked to different political parties. This arrangement makes it possible for the two key figures to work together in the SMC. In practice one or other is dominant. The analysis of interviews in this study also shows that in the schools where head teachers were enthusiastic and provided strong leadership, the quality of education was better than in other schools in the region. SMC Chairs usually took the lead in the (highly politicized) Terai, while head teachers appeared 
more likely to take the lead in the hilly areas. A range of political causes were identified behind the politicization of SMCs, some of which are stated below:

- There is a political vacuum at the local level due to the absence of local government. As government institutions, schools provide a platform for exercising local political power. Political parties endeavor to maintain their local profile through representation in the SMCs.

- Holding SMC positions, particularly the Chair, provides social and political status, which contributes to a political career in the party.

- Schools have become places for expanding political ideologies. SMCs can influence teachers, students, and parents to pursue their political agendas.

- $\quad$ SMCs can have indirect economic benefits (e.g., bribes) in teacher recruitment.

- Schools receive direct funds from government and the SMCs have influence on how to manage those funds. Supporting investment in school development (e.g., building classrooms) helps them gain social credibility.

- $\quad$ SMCs are not clear about their roles and do not receive any training.

Therefore, there are a number of political and economic motivations for competing for the SMC positions, especially the Chair. The aggressive decentralization processes inspired and assisted by development partners and project-based educational programming have influenced the trajectories in Nepal's education policies. Politicization in the education system is one of the unintended outcomes of the interaction between the global drive for educational decentralization and incompatible local contexts.

\section{Conclusions: Disjuncture between ‘Centralized Decentralization’ and Political}

\section{Localities}

The post-1990 governments in Nepal have adopted liberal economic policies creating a space for neoliberal policy reforms in public sectors including education. Several state owned companies were privatized to reduce public spending and enhance efficiency and accountability. The long-term effect of Nepal's educational decentralization policy seems to 
be the transfer of responsibility of public education to the poor people, while preserving private education, which maintains an elite system of education. This policy choice has been influenced by the neoliberal market economy through international organizations, particularly the World Bank, the largest education aid provider to Nepal. Nepal's bureaucracy and political leadership are dominated by high castes and traditionally privileged social groups who educate their children in private schools have bought into the idea of decentralization without adequate analysis of local realities, implications, or "piloting of the policy initiative" (World Bank, 2010). Hence, the collaboration between the national governments in the past two decades and international development partners has pushed the decentralization policy to the local levels without considering social, political, and economic realities of Nepali society.

In this chapter, I have argued that educational decentralization has a hidden motive of privatizing education in a bid to reduce public spending while encouraging competition, accountability, and participation at local levels. These global policy prescriptions accompany development funding, which can easily attract weak economies that have structural inequalities and elitism. Subsequently, these developing countries fall into the trap of dependency on international aid. Decentralization in this situation provides socially privileged groups with access to local resources and power. It serves primarily their interests, and thus reproduces political and economic structures and reinforces social hierarchies. Education decentralization does not necessarily empower marginalized groups in communities; rather it reinforces the traditional power of social control exercised by privileged groups in a different form. Finally, with no appreciation of local political economies, the consistent policy thrust from the center could create tensions among local and mid-level educational institutions and foster the development of a damaging culture in the education sector.

The interactions between relative poverty, post-war transitional politics, and unjust socio-political structures characterize the political economy of Nepal. The devolution of authority to local and regional levels cannot unconditionally benefit a community that harbors horizontal inequalities along caste and ethnic lines. 


\section{References}

Apple, M. (2004). Ideology and curriculum, 3rd Edn. London: Routlege Falmer.

Bhattarai, B. R. (2003). The political economy of the 'People's War'. In A. Karki and D. Seddon (eds), The people's war in Nepal: Left perspectives (pp. 117-164). New Delhi: Adroit Publishers.

Bourdieu, P. (1984). Distinction: A social critique of the judgment of taste. London, UK: Routledge and Kegan Paul.

Caddell, M. (2007). Private schools and political conflict in Nepal. In: P. Srivastava, and G. Walford, (Eds). Private Schooling in Less Economically Developed Countries: Asian and African Perspectives, (pp. 187-207). Oxford Studies in Comparative Education. Didcot, UK: Symposium, Available from http://oro.open.ac.uk/2892/1/CaddellSympChpt.pdf.

Carney, S., M. Bista, and J. Agergaard. (2007). 'Empowering' the 'local' through education? Exploring community-managed schooling in Nepal. Oxford Review of Education, 33 (5), 611-628.

Carnoy, M. (1999). Globalization and educational reform: What planners need to know. Paris: United Nations Educational, Scientific, and Cultural Organization (UNESCO).

Collinson, S. (Ed.) (2003). Power, livelihoods and conflict: case studies in political economy analysis for humanitarian action. London: Overseas Development Institute.

Cornwall, A. and Brock, K. (2005). What do buzzwords do for development policy? A critical look at 'participation', 'empowerment' and 'poverty reduction'. Third World Quarterly, 26(7), 1043-1060.

CERID. (2006). Education for All formative research report. Synthesis report of the case studies conducted in 2006. Tribhuvan University: Research Centre for Educational Innovation and Development.

Deraniyagala, S. (2005). The political economy of civil conflict in Nepal. Oxford Development Economics, 33(1), 47-62. 
DoE. (2010). Flash I Report 2067 (2010-011). Sanothimi, Bhaktapur: Department of Education, Nepal.

Dorling, D. (2011). Injustice: Why social inequality persists. Bristol: The Policy Press.

Edwards, R. M. (2011). 'Disconnect and capture of education decentralisation reforms in Nepal: implications for community involvement in schooling'. Globalisation, Societies and Education, 9 (1), $67-84$.

Hanson, M. (1998). Strategies of educational decentralization: key questions and core issues. Journal of Educational Administration, 36(2), 111-128.

McGinn, N. and Welsh, T. (1999). Decentralisation of education: Why, when, what and how? Paris: United Nations Educational, Scientific, and Cultural Organization (UNESCO). MoE. (1971). The national education system plan for 1971-76. Kathmandu: Ministry of Education.

Mohsin, M. (1972). Interview with Mohammad Mohsin. In I. Baral (ed.), National Education Plan: As They See It, (pp. 34-50). Kathmandu: National Education Committee Office. Onta, P. (1996). Ambivalence denied: The making of Rastiya Itihas in Panchayat era textbooks. Contributions to Nepalese Studies, 23(1), 213-254.

Poppema, M. (2009). Guatemala, the Peace Accords and education: A post-conflict struggle for equal opportunities, cultural recognition and participation in education. Globalisation, Societies and Education, 7(4), 383-408.

Stewart, F. (Ed) (2008) Horizontal inequalities and conflict: Understanding Group Violence in Multiethnic Societies. New York: Palgrave McMillan.

Tiwari, B. N. (2010). Horizontal inequalities and violent conflict in Nepal. In M. Lawoti \& A. Guneratne (eds.), Ethnicity, inequality and politics in Nepal, (pp.55-92). Kathmandu: Himal Books.

Watson, W. (2000). Multiculturalism. Buckingham: Open University Press.

World Bank. (1995). Priorities and strategies for education: A World Bank review. Washington, DC: World Bank.

World Bank. (2003). NEPAL—community school support project (Updated Project 
Information Document (PID)). Kathmandu: World Bank.

World Bank. (2010). Project Performance Assessment Report Nepal, Community School Support Project (CR. 3808), Available from

http://Inweb90.worldbank.org/oed/oeddoclib.nsf/DocUNIDViewForJavaSearch/FFBF0 9CBD4E802D185257788005B9EFA/\$file/PPAR Nepal\%20-

\%20Community\%20School\%20Support\%20Project.pdf

Zajda, J. and Geo-Jaja, M. (2009). The politics of education reforms. London: Springer. 